\title{
New Media: Connecting with Guests throughout the Travel Experience
}

\author{
Lisa Klein Pearo and Bill Carroll
}

Travel back in time 30 years. You read the paper during breakfast, scanning an ad for a luxurious Caribbean resort with a rate of $\$ 450$ per week. As you drive to work, you hear an ad on the radio for the same resort. The background music is a Bob Marley reggae jingle that you can't get out of your mind. In the waiting room at work, you spot an ad for that same resort in Conde Nast Traveler magazine. What a coincidence! Then, just before bedtime and right after Johnny Carson's monologue, you see an ad appear for that same hotel. That's it! You throw your arms around your partner, whistle Bob Marley's reggae jingle, and promise to call your travel agent in the morning. You both fall asleep dreaming of the romantic getaway to come.

The next morning, your travel agent finds you a better deal at another resort at the same destination. You book it. Months later, you savor your vacation memories. You had a good time despite several issues. Here's a black-and-white photograph taken outside the restaurant that the concierge recommended-a lovely location but not that great a meal. The hotel's plumbing was faulty and the room infested with bedbugs. You tell maybe five or six friends about your experiences and recommend they choose another restaurant and hotel if they go.

The marketing analyst at the resort where you didn't stay wonders why their newly renovated property had not achieved the expected bookings despite media placements on TV, radio, newspapers, and periodicals. The general manager wonders why that dump of a resort two miles away from the beach has such high occupancy versus his. Your travel agent goes to dinner on the 20 percent override commission paid by that dump of a resort.

Fast-forward in time 10 years from today. The video touch screen embedded in your kitchen table serves up your personalized morning news and a permission-granted, vacation-related, peergroup-vetted, rich-media-supported, date prespecified, budget-constrained, personally syndicated offer for a luxurious Caribbean resort for less than $\$ 800$ per week. You touch the "more details later" button and finish breakfast. On the drive to work, your personalized Sinus car radio program is interrupted with a brief blurb about the resort offer you saw at breakfast and your hands-free car phone crackles with the pleasant voice of Monica Marley (Bob's great-granddaughter) sent to you directly through the 
resort's app. You prefer a human voice to answer your questions. Monica answers all your questions via the car phone speaker.

During your lunch break, you see a Web video from the same Paradise Luxury resort showing your and your partner's avatars positioned in a resort guest room, dining room, pool, and other common areas. You touch the send button; record a voiceover-"This can be us," and send an instant message with the attachment to your partner.

That night, you and your partner use the remote device for the wall TV and book the hotel, based on glowing recommendations from friends and colleagues; select your room decor; make golf and spa reservations; and choose a restaurant based on reviews from young couples with your dining tastes. You choose entrees from the menu and your favorite wine. Six months later, as you slide into the limo arranged two weeks earlier from your mobile device, that same device chirps with a message from a member of your social travel community: "Get room on higher floor, face SE." You log into the reservation planner and enter your updated room request, along with an order for wine and cheese to be delivered shortly after your arrival. Five minutes later, as the limo driver drops you off, the bellman checks you in to your preferred room with his handheld tablet. Over dinner, your partner gushes, "This is even more wonderful than our avatar portrayed; the menu has our names on it, and they served our favorite wine; let's tell all our friends." You respond, "I posted our picture and a note 10 minutes ago to our friends; all 227 have received it, and so far 23 'like' it."

At the Paradise Luxury resort, the general manager is edified that her focus on quality service and social media management has produced measureable incremental contributions. She is also pleased with the real-time connectivity between her revenue management system and the full-channel marketing and distribution, as well as the large number of guest advocates. Meantime, the restaurant waiter got the biggest tip of the week from guests she never saw before and therefore decided not to accept the job offer from a competitive restaurant across the street.

As the use of social media expands, you must stay abreast of the increasing array of communications media options for how and when to reach your guests. "We refer to new media as those that extend the boundaries of traditional mass media and direct mail communications. These new media include Internet-based technology platforms that incorporate online banner and search-engine advertising, as well as social media and mobile media. This chapter explains how these new media options have affected your marketing communications. 


\section{Media Measurement and Players in Evolution}

Whether you are looking at new media or traditional media, the success measures haven't really changed. They are:

Additional sales that would not otherwise have occurred (net incremental contribution).

Expanded market share.

Increased effectiveness for complementary media.

Long-term relationships with guests and clients that lead to highly loyal customers and active advocates.

Even if the measurements are essentially the same, the process is in transition. Most of the specific measurements of media activities continue to fall short of directly gauging those success measures. Traditional media measurements could only tally reach, in the form of cost per thousand impressions (CPM) in audience. But what we really wanted all along was a way to record consumer interactions: the number and nature of customer contacts and how they converted to reservations. We could get a sense of this from phone call logs, sales contacts, property visits, and surveys, but this was still inexact.

With Internet and mobile communications devices, we now have better tools for measuring conversions. Companies in all industries have jumped on this opportunity, and independent research firm Forrester Research, Inc. estimates that new media will represent over 50 percent of advertising spending by $2014 .{ }^{1}$ As Figure 24.1 shows, the mix in new media spending will change as well by 2014 .

Chances are that your hotel or restaurant uses an online travel agency (OTA) for distribution, such as Expedia, Travelocity, or Open Table. Your property or brand probably also has its own Web site for reservations, and many customers use OTAs as a source of information, and then book on a hotel's site, according to PhoCusWright research. ${ }^{2}$

Your Web site's success is measured by the number of unique visitors to your hotel or brand Web site, the percentage of those visitors converted to bookers, and the revenue generated from those bookings. With the growth of social media we are expanding this to include measures of the value of referrals. This is a great step beyond media reach measurements. The Web-based metrics relate costs (of the online effort) with the revenue contribution generated. We still don't know, however, whether some or all of the revenue was incremental or simply a distribution channel shift of existing customers. 
Your ability to correlate cost with incremental contribution is even more tenuous with OTAs. It's hard to determine whether the transaction produced by the OTA was incremental and shifted share from your competitor or whether your guest would have booked anyway. If the latter, that booking could cost you 20 to 30 percent of the revenue you would otherwise have received through a regular booking. There is strong indication that the OTAs give you incremental bookings, though. For instance, Cornell research indicates that there may be anywhere from a 7 percent to a 26 percent increase in reservations through your site based on your position on the OTA display. ${ }^{3}$ That is, if you're at the top of the display, people see your property and they are more likely to book through your own site. Given this, the average cost of an OTA booking may be closer to 7 or 10 percent, in terms of lost revenue. Although questions remain, that study is based on the principles of search engine marketing and search engine optimization. Both focus on getting your property near the top of any Web search, whether it's an OTA display or a simple search engine query.

Figure 24.1

\section{U.S. Interactive Marketing Forecast}

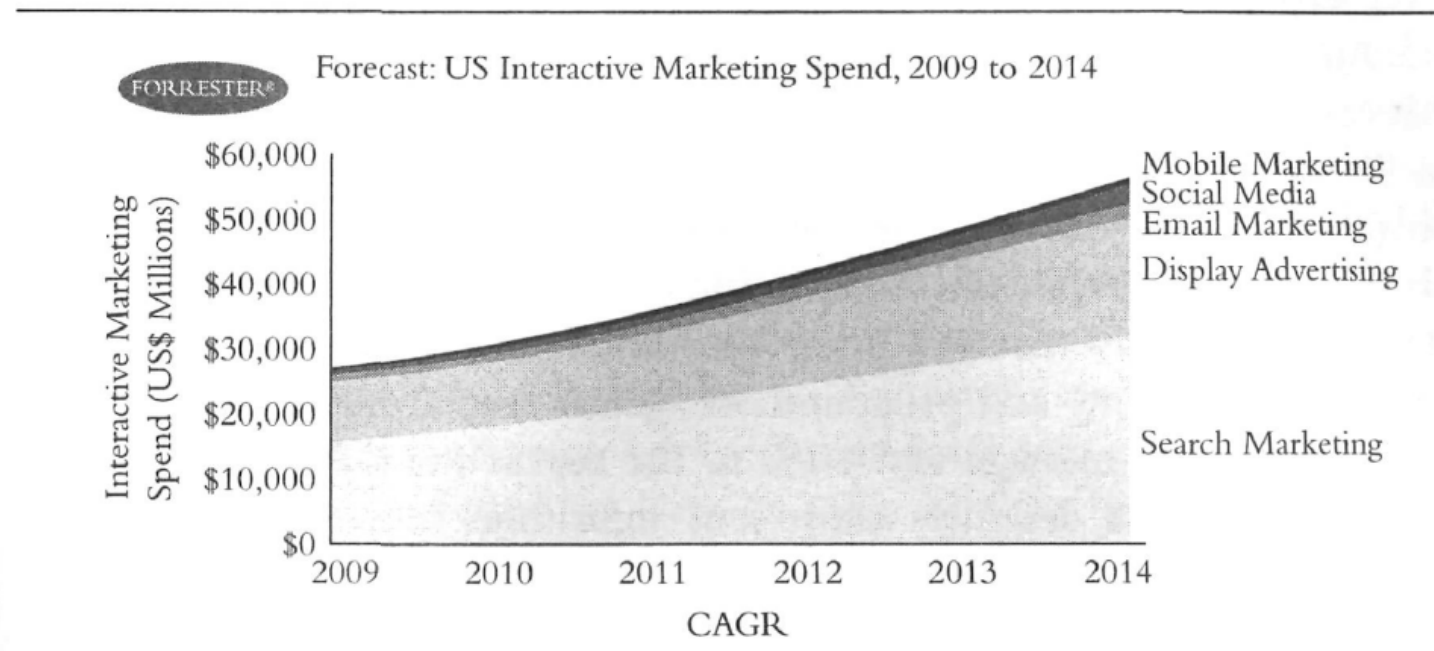

Source: Reproduced by permission from Forrester Research, Inc.

\section{Search Engine Marketing}

Search engines in all forms have changed the hospitality marketing playing field. An otherwise obscure hotel can have its "name in lights" if it determines what consumers are seeking when they search for hotels in a particular market. Through search engine marketing (SEM) and search engine optimization (SEO), hotels can increase the chances that their property comes up near the top of 
searches on Google, Bing, and similar sites. SEM involves bidding on keywords that will bring your hotel to the top. The former pits hospitality consultants and programmers against search engine designers to get a hotel's brand message and URL to the top of the search results page, while search engine designers churn out algorithms to provide users only what they want to see.

Choosing the correct keywords to bid on (while minimizing click costs) has created a whole line of business for media advertising agencies like TIG, Milestone, and TravelCLICK. Among other services, these companies analyze search engine mechanics so that their clients design their own Web sites and choose words and phrases that move their Web sites to the top of search engine screens.

Measurement metrics for SEM include the number of search page views containing the brand site URL, the number of click-throughs to the brand site, percentage of click-throughs converted into bookings, and the revenue generated from those bookings. In turn, there are associated pay-per-click and SEO costs. While such metrics are more informative than the cost per impression from traditional media, they still fall short of decisively measuring incremental net revenue contribution. We still don't know whether the keyword purchases or SEO expenditures really generated new business or whether the hotel would have gotten those bookings, anyway. This is a particularly relevant issue when you are bidding for your own brand name. Of course, if you don't bid on it, your competition will, and you may not be found when the consumer is "searching" for you.

One measurement that we still don't have at this writing is the full chain of click-throughs that precede a booking. Search engine analytics provide metrics only for the "last click" from a keyword listing. Measuring only the last click, though, may misrepresent the real net contribution of optimizing keywords or keyword bidding. You can't be sure where the user was in the buying sequence-dreaming, planning, or booking - when the search engine click-through occurred. You also can't know what other sites the user visited before the last click.

Keywords that optimize a search are essential. It is likely that search engines will record a larger relative number of "last clicks" from keywords that contain your brand name because the user is more likely to be searching for a particular brand at the late stage of the search process when she's about to book. Given the search engine algorithms, you want to be certain that your brand comes up when the user is searching for it. At the same time, you may have determined that some generic, destination, or other nonbrand words are influential in capturing searchers. Your hotel's location, descriptors of the destination, and features of your property might be critical to a search. Consumers may start their search by looking for "seaside" or "mountain view," for instance, so your site could include those 
phrases if they apply. Then, at different points in the buying sequence, other optimizing keywords may come into play.

Search engine analytics can suggest some of these phrases. The analytics also can be informative from a competitive standpoint so that you know whether you are getting your fair share of views and clicks from brand and generic keywords.

\section{Social Media}

So far, we've been discussing the traditional search engines, but in a way they are already old technology. We say this because in 2010, Facebook eclipsed Google as the most visited site on the U.S. Internet. ${ }^{4}$ This heralded the entry of social community marketing as a major force in hospitality media marketing. Coincidentally, the potential intersection of online travel community formation with search, shopping, and mobile applications (apps) portends even more changes in future hospitality marketing media approaches.

\section{Social Media: Evolution or Revolution?}

Cindy Estis Green

\section{Managing Partner}

The Estis Group

The shift by consumers to social media and new media tools began in the late 1990s, but the marketing community took about five more years to start responding. When marketers did engage with the new media channels, they found that the dialogue that occurs in these channels is on a consumer-to-consumer basis, virtually cutting out the brand voice.

The implication for marketing strategy is profound. With the plethora of new channels and a notable shift in consumer behavior, the once time-honored approach of aligning product, pricing, promotion, and path no longer applies.

The hospitality consumer's purchase decision process is inexorably altered. Most consumers no longer travel the predictable linear path that represents the process from a premarket need through searching, planning, prevalidating, booking, postvalidating and enjoying a hospitality experience. Through the use of social media, many consumers follow an iterative loop in which they continually interact with friends, family, and even strangers to gather information and verify expectations in parallel with their booking process, and, even 
more of a change, postexperience. Consumers share stories about their hospitality activities, including photos and video, and make this content available in the public domain.

The variables in a new media marketing plan have expanded by an order of magnitude. Hospitality marketers have to consider reengineering their infrastructureorganizations and budgets-to successfully manage this shift.

\section{Marketing Strategy in a New Media World}

Three C's of marketing are emerging: content, context, and conversations. Product decisions have to be infused with a content plan. This is not only brand-made content, but incorporation of consumer-generated content. The context of the product imagery requires a nuanced eye. A brand's products and services can be represented in diverse environments, many of which are not under the control of the marketing team. Whether it is a blog by a travel agent, a Twitter (microblog) feed by a business traveler, a series of YouTube videos posted after a trip by leisure guests, or a meal description by a restaurant guest, this content can have a greater impact on the brand image than anything a brand posts.

The brand's inability to mandate an image through promotional messages means they have to learn to influence these conversations, which often diverge from what the marketing team intended. The residual content amassed by these conversations has opened a new arena for hospitality called reputation management. Besides the direct brand message, consumers have unfettered access to each other's commentary, only part of which may be factually accurate, and most of which is purely subjective. In response, the hospitality marketer needs methodology for managing the brand while immersed in this murky and uncontrolled sea of consumer opinion.

The new media world includes booking channels that allow messages and message channels that enable booking. The hospitality marketer must be mindful of the many combinations of sites a consumer will visit. Further, participation in some sites influences success in others. For example, a high level of video, blog posts, and other social media output can improve a brand Web site's ranking in a search engine. The hospitality marketer has to decide the extent to which they will proactively participate in a channel and when they will passively observe the hospitality consumers' booking process. There is a cost associated with each of these channels and finding the optimal mix of channels that deliver the most business at the lowest cost is the marketer's challenge. 


\section{Summary}

The popularity of social media sites is dynamic and needs to be monitored. Today's Facebook, Twitter, Trip Advisor, Yelp, and YouTube may well be replaced by other sites over time. What won't change is that consumers will continue to interact with each other, they will be skeptical of brand messages, and they will expect full access to a rich and wide array of content. But as hospitality firms gain more expertise in navigating the new media environment, they appear to be taking advantage of three primary applications of social media: (1) managing and burnishing a brand image, (2) engaging customers and prospects by providing higher levels of customer service and more relevant interaction, and (3) conveying tactical sales offers delivered in an appropriate voice and channel.

The first use of social media in connection with hospitality was peer-to- peer reviews of hospitality services (such as consumer comments found on TripAdvisor and Expedia) and instant text messaging among community members. In 2010, PhoCusWright reported that 8 of 10 travelers who had booked online had first read a review of travel-related services. ${ }^{5}$ PhoCusWright also reported that unique visitors to peer-to-peer review sites like TripAdvisor and IgoUgo were growing at a rate of 50 percent per year, and TripAdvisor hosted nearly 10 times the number of visitors as its nearest competitor. ${ }^{6}$ Remarkably, during 2009, the growth in the number of peer reviews posted to OTA sites was three times greater than peer-to-peer review sites. Since Expedia owns TripAdvisor, and Travelocity is connected with IgoUgo, we can conclude that the OTAs have become a major force in social media marketing. Essentially, OTAs strategically positioned themselves to incorporate social community-based peer-to-peer reviews as part of their service.

Facebook introduced its "I like" and "Social Graph" functions in 2010. We think that consumers will put greater weight on friends' Facebook recommendations than on those of strangers on peer-topeer sites. Friendship may not be the optimal indicator of shared interests, but until peer-to-peer review sites add greater capability for consumers to identify like-minded reviewers, Facebook may be the most efficient way for consumers to sift through so many opinions. We will also likely see more hospitality marketers offering incentives to users to connect with the brand in order to build an audience and search influence.

Hospitality marketing structured around other social media activities is still coalescing as we write this. We don't know whether the value of Twitter's promotion and information messaging will 
grow or shrink or whether Hogging will remain influential, but it's nearly a sure bet that some form of realtime, consumer-driven messaging will continue to dominate consumer search sources. Most major U.S. chains are still experimenting with these sites to raise awareness regarding their brand at every consumer contact point.

Most critically, you need to work on managing brand reputation in social media by monitoring comments and participating appropriately, in part by responding to posts in blogs and rich media sites. You have to monitor the sites to see if your hotel's name comes up, or rely on software that monitors social media sites and provides formal reports on your competitive position.

As a hotel employee or manager, you should not post on social media unless you are authorized to do so, to protect and support your brand. Carefully managed employee participation at all levels can be beneficial. Your hotel might use tweets to extend service with helpful blast messages to guests who are following your hotel (e.g., as an extension of concierge service) and to produce promotional and merchandising messages.

\section{Measuring Social Media Success}

You'll find that social media success metrics are still in the formative stages. They include: (1) measures of attraction that social media communities have with your brand or property; (2) the relative level of "buzz" (online mentions) you're getting; and (3) the relative sentiment of communities, including peer-to-peer reviews. As a manager, you will want to know your customers' position in terms of popularity or "connectedness" (by name, if possible). This includes:

. Those who want to hear from you on a regular or specified basis

. Those who have spoken to their communities about you-positively and negatively

- Those who are active and frequent advocates or critics of your hotel

Companies like TIG Global, Milestone Interactive, and TravelCLICK are active in measuring where you stand against your competitive set in social media. These metrics fall in two areas: awareness and sentiment. You define your competitive set, and the analytics firms give you metrics that include indices of social media awareness about your property compared to competitors, based on the buzz (e.g., mentions in blogs, peer-to-peer reviews, and media posts), and based on the nature of the sentiment being expressed. These firms apply proprietary algorithms that analyze online communications and also compile quantitative scores or rankings. These tools are available to marketing media managers to help you monitor and protect your brand as it appears on social media sites. 


\title{
The Mobile Revolution and Hospitality Distribution
}

\author{
Norm Rose \\ President \\ Travel Tech Consulting, Inc.
}

Mobile technology will change the guest experience in a way that will likely equal or surpass the Internet's impact. Far from being just an additional touch point, mobile devices constitute a new platform for customer interaction-providing applications and capabilities that were not possible on prior devices. With nearly one-third of the U.S. population owning a smartphone at this writing, ${ }^{7}$ the opportunity continues to grow. Seventy-one percent of frequent business travelers use a smartphone for both business and leisure trips. ${ }^{8}$ The hospitality industry is particularly well positioned to use mobile technology to enhance the guest experience, promote onsite and local services, and improve operational efficiency. Much in the same way each hotel must have a Web presence, it is essential that every hotel develop a mobile strategy.

The first step is to reformat your Web site to allow mobile browsing. Even with today's latest smartphones, viewing a standard Web site can be challenging. Many companies can provide you a transcoding service that takes your current Web site and extracts the key elements for viewing on a mobile browser.

The next thing to consider is a downloadable application. Triggered by Apple's iPhone, there has been an explosion of app stores where customers can download applications to their phones. A recent study predicted that mobile app downloads will jump from 7 billion in 2009 to almost 50 billion in 2012 with the market worth $\$ 17.5$ billion. ${ }^{9}$ App stores are now available on every smartphone platform. There are two options in considering a downloadable app. You can create an application for your hotel, or you can partner with an existing provider of location-based services. This choice depends on the number of properties you own or manage, your budget, and your guest profiles. Unfortunately, fragmentation of mobile platforms will continue for the foreseeable future, so you'll need apps written for different devices. Choosing which platform to start with depends on your location and the characteristics of your guests. If you primarily cater to business travelers, a RIM Blackberry app may be best. If you are based outside the United States, you may want to look at Nokia's Symbian operating system as an initial target. Many hoteliers have selected the iPhone to create their application due to its 
popularity and functionality. Google's Android operating system has emerged as a major force embraced by a variety of device manufacturers and therefore should also be considered.

Your mobile apps should allow booking, check-in, and check-out. Such apps are already available through the mobile Web or branded downloadable apps on the iPhone, Blackberry, or Droid platform. Mobile concierge applications are a natural for the hotel industry, shifting the physical concierge costs to a location-sensitive personalized guide to local restaurants and attractions. Marketing through upgrades, spa reservations, add-ons, and mobile coupons can help hoteliers promote on-property services, restaurants, and local merchants. Ancillary purchases can be facilitated through mobile payment capabilities. Companies such as OpenWays are pioneering electronic room entry via mobile phones.

But this is only the beginning. Smartphones are increasingly acting as sensors that interact with the physical world by providing instantaneous information that influences guest behavior. An example of this is augmented reality applications such as Trip Wolf that overlay location-based information with destination guides. Annotating the physical world has its challenges, as crowd sourcing will influence guest decisions on restaurants, activities, and merchants.

Since users are storing their personal preferences and information on their smartphones, personal information (with proper opt-in controls) can be used for guest segmentation and more targeted promotions and dynamic rate offers based on guest value. The mobile phone will be used to enhance the conference experience, for instance, allowing you to identify attendees with similar interests and goals. The mobile device will provide personalized alerts to customers based on their preferences, providing them instant destination information based on their location. The smartphone will truly live up to its name by delivering updates of applications and prioritizing the apps most important for your customers' location and situation.

The mobile revolution promises to change hotel distribution as radically as the Internet itself. Innovation will continue, with thousands of third-party developers innovating on smartphone platforms. It is essential that hoteliers embrace this new platform and create applications to improve the guest experience, providing a new platform for guest interaction. 


\section{Mobile Media}

Mobile applications are already changing hospitality distribution. Although frequent business travelers are current heavy users, leisure travelers will soon catch up. As examples, travelers can now download their boarding passes on their smartphones, and most major U.S. hotel chains have mobile apps. For the moment, we consider mobile as a subcategory of new media, but we expect that technological advancements will blur these boundaries. The most popular hotel apps empower travelers to get directions, make last-minute reservations changes, and change bookings. ${ }^{10}$

Mobile apps can also create efficiencies for travelers and hotels by allowing mobile device check-in, room assignment, and check-out. More advanced applications include on-property merchandising. So far, companies have extended their Internet-based applications to mobile platforms, but we see these mobile devices as enabling communications, which can be more time and location sensitive.

Similar to hotels, restaurant apps involve shopping and searching, in addition to making, canceling, and changing reservations. Early mobile restaurant applications were centered on getting directions and finding parking for restaurants, plus sharing information with others about food quality and service.

We think you can expect mobile apps to go beyond simply refitting existing brand Web site applications because you can do much more for your customers through the mobile platform. As time goes on, you'll be able to use the mobile user's identity, relationship, physical location, and context to refine the information and services you present to these customers, say, expediting check-in for a loyal guest. Room check-in or keyless access will require more technological effort on the part of hotels and more widespread use of applications by mobile device users. At the moment, these apps might set your property apart, but before long they'll be "table stakes." Your frequent guests will simply expect to walk in and use their phone to open their room.

A particular opportunity for mobile apps is to market to your guests during their stay (and not just before). With mobile apps, you can remain engaged with the consumer and encourage consumerto-consumer communication during a hotel stay, all with the goal of improving the guest experience, while gaining incremental revenue. 


\section{Media: The New and the Newer}

Taking a broad, philosophical approach, Figure 24.2 depicts the evolution of media in the hospitality industry from the perspective of media's role in the consumer decision process. In the era of print and television, as we said, media spending and measurement was determined by reach, measured by CPM. The goal was to reach the largest and most targeted audience at the lowest cost. In most cases, these messages reached consumers before they had actively begun to search for specific service providers-in their "dreaming" stage. The eruption of Internet search engines moved the marketing model to pay-per-click analysis and marketing spending, with measurements of immediate response to search results. These messages reached consumers at a late stage, when they were gathering information prior to their actual decision. Consumers had moved from the dreaming stage to seeking information by category, location, or even brand.

With the relatively recent availability of consumer-to-consumer social media, consumers can actively search for opinions, activities, and experiences of those with whom they are connected. This connection is at a fairly late stage of the purchase decision process. Moreover, as indicated by the shading in Figure 24.2, consumers can then use these networks to share their experiences with others who are at the same decision stage. The real innovation, which is enabled by mobile apps, is that people can gather information during a trip, including getting recommendations on destination activities, restaurants, and transportation. Thus, marketers can use this channel to let their guests know about spas, concierge services, restaurants, and room service, thereby enhancing the guests' on-site experience.

Even more interesting and potentially game changing is the notion that your current guests will interact with other current, future, and past guests during their stay. This means you will be engaging with consumers during their actual experience, and also with other consumers that now have access to the property's (and destination's) information. Consequently, the link between consumers is now completed by connecting those in the midst of their experience with those who are "before" and "after," as shown in Figure 24.3. For this purpose, consumers can use third-party applications such as Foursquare and Gowalla or proprietary applications such as those being developed for specific properties and destinations, such as Disney World. Thus, marketing must focus on enabling and facilitating connections among (the appropriate) consumers at all stages in their travel experience. These connections must tie in tightly with the consumer decision-making process, as highlighted in Figure 24.2. 
Figure 24.2

Consumer Use of Media During Hospitality Purchase and Use Stages

\begin{tabular}{|c|c|c|c|c|}
\hline 1 & & \multicolumn{3}{|c|}{ Decision Stage } \\
\hline Media Focus & Measurement & Before & During & After \\
\hline 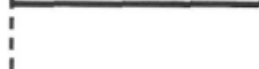 & & & & \\
\hline Print/TV & Reach and CPM & & & \\
\hline $\begin{array}{l}\text { Computer: } \\
\text { Internet Search }\end{array}$ & $\mathrm{CPC}$ & $\mathrm{X}$ & & \\
\hline $\begin{array}{l}\text { Computer: Social } \\
\text { Media }\end{array}$ & Followers/Fans/Connections & $\mathrm{X}$ & $\mathrm{X}$ & $\mathrm{X}$ \\
\hline Mobile & Check-Ins/Location & $x$ & $\bar{X}$ & $\mathrm{X}$ \\
\hline
\end{tabular}

Note: While the shading used is solid, a better representation might show blendings between stages as decision making occurs repeatedly throughout any hospitality experience as guests choose meals, spa treatments, room service, etc.

Heavy use $\square$ Moderate use Little to no use

A key point here is that the new media do not replace the old, but instead add value at different stages of the consumer decision process. What now challenges you as a hospitality marketer is to identify when a consumer is ready to move from one stage to the next and to supply the appropriate tools. Identifying how and what information your consumers need at each travel stage will enable you to provide the right links and connections to that consumer. Consumers do indeed have the power to gather information from almost anyone, anywhere now, but you as a marketer also have the power to communicate with anyone, anywhere to give them exactly the information they need. With new media, your constraints involve only access and engagement. You must make it valuable for the consumer to give you access to them and to provide incentive (intrinsic or extrinsic) for them to engage with you and with other consumers. 
Figure 24.3

The Flow of Consumer Conversation

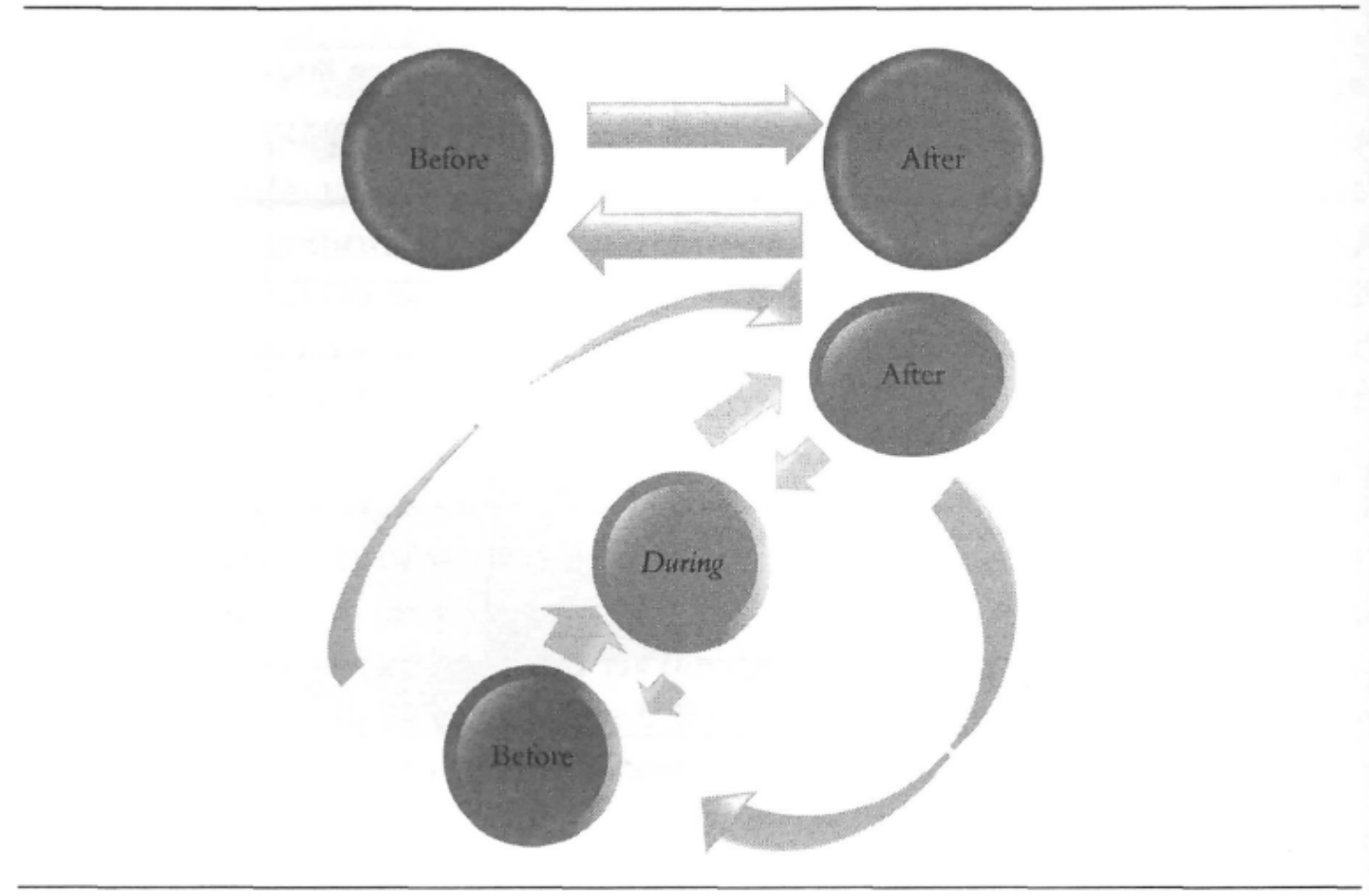

\section{Restaurants: So what do I do?}

As a restaurant manager, you need to view new media primarily as an opportunity to get to know your customers. With new media, including social networks and mobile platforms, you can help consumers make dining decisions by providing them with the right information at the right time and encourage your best customers to help other customers make reservation decisions. The following suggestions can help you move toward these goals:

Before the experience. Monitor and respond to peer-to-peer reviews on the most relevant sites for your restaurant(s). Use premium services to address interested customers on the most valuable sites. Find ways to track your customers' use of these sites to post and read reviews.

During the experience. Use location-based applications such as Four Square to understand repeat purchase patterns and test promotional influences directly. Recognize and reward frequent visitors. Rather than simply assessing how many additional covers or meals a promotion attracts, you can now evaluate 'which customers they attracted. You can assess whether these were incremental visits by 
"light users," trial visits by new customers, or loyal customers who merely shifted to a different daypart.

After the experience. Use social media as an opportunity to extend your listening beyond your dining room. Monitor the changes in the volume and tone of these conversations (for you and your competitors). Use microblogging tools, such as Twitter, to join in the conversation.

\section{Hotels: So what do I do?}

For hotel marketing managers, the opportunities are similar but focus less on knowing who the customer is and more on the why and how of the customer's visit. That is, interactions through new media can help you understand the objectives for customer's visit, as well as the information gathering paths for fulfilling them. The following suggestions outline the key strategies:

Before the experience. In the planning stages, continue to use SEO and SEM to target your customers. Focus on optimizing results on Google, Facebook, and Twitter, among others. Once the reservation has been made, use e-mails and mobile apps to engage customers in the specifics of planning their experience before they arrive. Early engagement extends the brand immersion.

During the experience. Onsite mobile apps allow the hotel to serve as the liaison or assistant in customers' spontaneous decisions for incremental services. With the added revenue comes added knowledge about the choices guests make throughout their stay. Encourage the customer to engage with other customers onsite through appropriate networking tools.

After the experience. As with restaurants, continue to monitor peer-to-peer review sites. Enable customers to use your applications to provide specific advice to other guests and to leave direct feedback for you. Provide customers with the incentives to continue the relationship with discussions, photos, and videos through social networks.

As a hotel marketing manager, your goal should be to act as the customer's primary "liaison" to his travel experience before, during, and after his travels. Technology has changed the focus of your interactions at different stages of the experience. Now, with the growth of mobile platforms, you can maintain contact throughout the guest's experience by providing planning tools (before), experiential tools (during), and feedback and sharing tools (after). Beyond that, you can gather information on and make connections with guests of competing hotels. Finally, you can measure your marketing response continuously and implement simple tests of new promotional offers with little cost and low risk. 


\section{Conclusion}

New media represent opportunities for hotel and restaurant marketers both to acquire and retain customers. You can use new technologies to (1) encourage your loyal customers to recruit new customers through social media, and (2) find new customers directly through the interests they express. To retain guests, you should evaluate new media as channels for listening, monitoring, measuring, and responding throughout the guests' experience. For both acquisition and retention, return-on-investment measurement will help you determine which activities have been successful, even though not all will generate revenue immediately. Some new media activities such as gathering customer feedback, may simply be more effective substitutes to older ways of doing business. In general, you must be part of the changing world of media, integrating the old with the new.

\footnotetext{
${ }^{1}$ S. V. VanBoskirk, "US Interactive Marketing Forecast, 2009 To 2014, Forrester Research, Inc. (July 2009).

${ }^{2}$ C. Rheem, PhoCusWright Consumer Travel Report, Section 5, 2009.

${ }^{3}$ C. Anderson, "The Billboard Effect: Online Travel Agency Impact on Non- OTA Reservation Volume, Cornell Hospitality Report 9(16) (2009).

${ }^{4}$ Hitwise Industry Report, December 2010 (http://www.hitwise.com/us/presscenter/ press-releases /facebookwas-the-top-search-term-in-2010-for-sec /).

${ }^{5}$ PhoCusWright, Consumer Technology Survey (November 2009).

${ }^{6}$ PhoCusWright, Social Media in Travel: Traffic and Activity (April 2010).

${ }^{7}$ NPDGroup, http://paidcontent.org/article/419-deep-discounts-on-smartphonesdrive- u.s.-adoption-rates-tonearly-a-thi /, 2009.

${ }^{8}$ PhoCusWright, Mobile: The Next Platform for Travel, www.phocuswright.com/research_publications_buy_a_report/585, 2010.

${ }^{9}$ Chetan Sharma Consulting, mashable.com/2010/03/17/mobile-app-market- 17-5-billion/, 2010.

${ }^{10}$ C. Schetzina, Consumer Technology Survey, 3rd ed. PhoCusWright (December 2009), Part Five.
} 